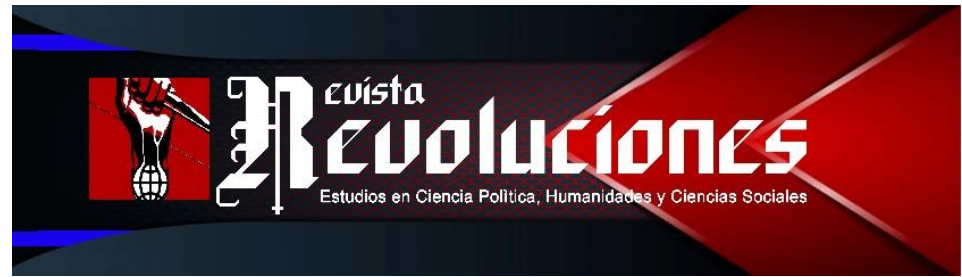

\title{
TIEMPOS DE LIBERTAD. EL DURO APRENDIZAJE REPUBLICANO DEL PERÚ INDEPENDIENTE
}

\author{
Times of freedom. Peru's hard republican learning after the \\ Independence \\ Héctor Palza-Becerra ${ }^{1}$ \\ UNIVERSIDAD NACIONAL MAYOR DE SAN MARCOS \\ PERÚ \\ hpalzab@gmail.com
}

DOI: https://doi.org/10.35622/j.rr.2021.05.005

Recibido: 08-VI-2021 / Aceptado: 24-VII-2021 / Actualizado: 28-VII-2021

\section{Resumen}

El tránsito a la República, una vez lograda la independencia en el Perú, estuvo lejos de constituirse en régimen democrático burgués, debido a que la pervivencia de las relaciones sociales y valores del Perú colonial eran un obstáculo para tal propósito. Por tal motivo, aprender a vivir en un sistema republicano resultó un aprendizaje difícil, puesto que el ser y la conciencia del ayer virreinal todavía seguía vigente en nuestro medio. De esta forma, el naciente Estado reprodujo las formalidades de un Estado moderno, que esgrimía un doble discurso; por un lado, abrazaba los ideales de una prédica nativista y, por el otro, rechazaba la real integración de las masas no blancas en la vida política.

Palabras Clave: República, Estado moderno, ciudadanía, libertad, Nación.

\begin{abstract}
The transition to the Republic, once independence was achieved in Peru, was far from becoming a bourgeois democratic regime, due to the fact that the survival of the social relations and values of colonial Peru were an obstacle for this purpose. For this reason, learning to live in a republican system was a difficult apprenticeship, since the being and consciousness of the vice-royal yesterday was still in force in our midst. In this way, the nascent State reproduced the formalities of a modern State, which wielded a double discourse; on the one hand, it embraced the ideals of a nativist preaching and, on the other, it rejected the real integration of the non-white masses into political life.
\end{abstract}

Keyword: Republic, modern state, citizenship, freedom, Nation.

${ }^{1}$ Historiador peruano por la Universidad Nacional Mayor de San Marcos.

ISSN: 2710-0499 ISSN-L: 2710-0480

Esta obra está bajo una licencia internacional Creative Commons Atribución 4.0. 


\section{INTRODUCCIÓN}

La independencia y la instauración de la república, fue un proceso difícil y controvertido, en razón de la misma complejidad de este proceso que surge de la desintegración del Imperio hispano. En este sentido, el aprender a ser libres no fue de suyo simple, porque no estábamos preparados para ello. La carencia de esta preparación nos llevó por caminos inciertos, en vista que, dada la inexistencia de una clase dirigente, será la aristocracia colonial limeña a la que le toco fundar este endeble Estado de derecho en un medio colonial. Nomenclatura política que lejos de concretarse en una auténtica independencia, autodeterminación y soberanía, no tuvo los alcances deseados, puesto que quienes asumieron el poder conformaron un grupo monopólico que copó al nuevo régimen, con la finalidad de mantener ilesos sus beneficios, delineándose como una élite que limitó los horizontes de las grandes mayorías.

De manera que la república no se constituyó en un Estado verosímil, porque para serlo necesitaba liberarse de ataduras y renovarse constantemente para mejorar el destino de las generaciones venideras, en base a la aplicación de reformas políticas, sociales, económicas y jurídicas. Parte de esta dificultad nace del hecho mismo de nuestro nacimiento, ya que el apresuramiento de los libertadores y los ideólogos republicanos por afirmar la independencia, los llevó a elaborar sobre la marcha, un programa que recogió algunos elementos reformistas de la administración colonial española, y con ella se lanzaron a la tarea de convertir al virreinato en una república. Por eso es que, desde la instauración de la primera república, son completamente inoperantes los conceptos de soberanía popular, imperio de la ley y virtudes republicanas.

En virtud de estas consideraciones, el propósito de este estudio es examinar, en el plano político, los desafíos que tuvo que afrontar nuestro país en el proceso de construcción de una vida republicana viable y de cómo la promesa para el desarrollo de esta empresa, de la que hablaba Basadre en uno de sus ensayos, fue un elemento distractor, detrás del cual se ocultó una realidad declarativa y virtual. Precisamente, el énfasis estará puesto en ver cómo, a través de un doble discurso, sin dejar de ser como es, el Perú se reviste de modernidad para ser asumido por la aristocracia criolla.

El tema, en el contexto de la celebración por el bicentenario de la independencia peruana, viene generando espacios en los se ha ido incorporando esta temática. Esta perspectiva contribuye a ampliar las interpretaciones sobre el proyecto político, que busco hacer del Perú una república liberal. Este interés acapara la atención de los estudios de Hamnett 1978, Gootenberg 1989, Anna 2003, Chiaramonte 2004, Méndez 2014 y Sobrevilla 2019. Brian Hamnett, por ejemplo, identifica los movimientos revolucionarios en México y el Perú entre 1800 y 1824 . En el análisis de este proceso, este autor realiza un balance interpretativo del creciente fermento libertador que anima a los grupos más fervorosos por la independencia de los dos virreinatos. Por su parte Paul Gootenberg, estudia el impacto de la incorporación de la economía peruana a la economía globalizada decimonónica. Gootenberg pone de relieve la historia del temprano nacionalismo peruano, tanto en sus conflictos políticos y comerciales 
con el liberalismo económico, como las influencias extranjeras que gravitaban en el desarrollo del Estado republicano durante el siglo XIX.

Estos avances en la investigación, también se han visto enriquecidas por las investigaciones de Timothy Anna, quien ofrece una entrada para comprender la caída del régimen español en América del Sur. Anna señala que el dilema que se le planteó al Perú, fue renunciar al dominio colonial o seguir en el sistema. En este sentido, estima que las élites peruanas no estaban comprometidas con la independencia. De igual modo, José Carlos Chiaramonte, nos ofrece claves para una interpretación más apropiada de la azarosa política de la época, así como los conflictos en torno a la organización de los nuevos Estados. Cecilia Méndez, en lo que concierne al objeto de nuestro estudio, describe la construcción del Estado nacional, en un contexto inestable, signado por la cancelación del dominio colonial. De este modo, deja en claro cuáles son los elementos bajo los cuales se edificó el nuevo orden político y sus componentes (territorio, población y Estado). Muy cercana a ella, Natalia Sobrevilla reflexiona sobre las experiencias políticas de los inicios de la república. La autora señala que después de las guerras de independencia, y casi durante todo el siglo XIX, en el Perú se produjo un largo proceso de consolidación política, económica y social.

Este artículo busca incorporarse en esta área de trabajo, ampliando y revisando algunos temas y conceptos presentados por los autores antes citados. Nuestro estudio señala que la ausencia de instituciones autónomas o autogestionarias de participación popular en asuntos políticos o económicos internos en el virreinato, no le permitieron generar a la población una conciencia participativa en asuntos de interés individual y común. Lo cual nos habría preparado para vivir en un sistema republicano. Por lo que esta carencia dio como resultado la fundación de un Estado, caracterizado por la ausencia real de una ciudadanía, la presencia de una libertad limitada a una minoría y la falta de una clase dirigente capaz de conducir los destinos de la nación.

\section{DESARROLLO}

\section{El Perú después de la guerra de independencia}

¿Hacia dónde iba y hacia dónde ha ido el Perú tras la independencia? La respuesta plantea muchos escenarios posibles, pero lo que sí es seguro, es que la ruta seguida estuvo llena de una serie de incertidumbres e indefiniciones, pues quienes tuvieron en sus manos la oportunidad y la responsabilidad de encausarla, no supieron qué hacer luego de que esta importación se concretizara, gracias a la intervención mayoritaria de fuerzas militares extranjeras, comandadas por el general San Martín.

Más allá de una efervescente retórica, no existió el desarrollo de un plan que permitiera afrontar el reto de la institucionalización del nuevo Estado, lo que devino -entre otras cosasen la oposición entre monarquistas y republicanos, en virtud de la inexistencia de un cuerpo doctrinal único, que sirviera de base para la estrategia que debía adoptar la naciente

Revista Revoluciones $\mathbf{- 5 6 - V o l . ~ 3 , ~ N o ~} 5$ (2021), pp. 54-72

Esta obra está bajo una licencia internacional Creative Commons Atribución 4.0. 
república. La limitadísima capacidad de respuesta para hacer frente a los agudos problemas del país, nos colocó así en una posición extremadamente vulnerable.

Considerando los perjuicios que esto ha ocasionado en el devenir de nuestra vida republicana, examinaremos algunos caracteres de esta matriz, que configuro a nuestro país como un ente indeterminado. Para el efecto, tomaremos como referente la interacción de dos variables, consistentes en la polarización en torno al sistema político que debía adoptarse y el consiguiente reacomodo que se produce a partir de la formalización establecida.

\subsection{Después de la independencia ¿qué?: entre el monarquismo y el republicanismo}

En un sentido amplio, la independencia no reportó nada nuevo a la futura composición interna de la naciente república (Gonzáles y García 1987, 11). En esta perspectiva, según las impresiones de Carlos Contreras, el Perú no empieza con el pie derecho su vida independiente, ya que su independencia tiene dos taras: una, el de ser un fenómeno tardío; y la otra, el de ser impuesta más que buscada. ${ }^{2}$

De modo que, nuestra independencia no nació de una motivación histórica propia, como, por ejemplo, en Argentina o Chile, donde tuvo una mayor maduración, porque eran regiones más periféricas. En el Perú, en cambio, al ser el centro de la dominación española en el sur, esto hizo que se retrasase la construcción de una élite nacionalista. 3 Por lo cual, los grupos sociales no estuvieron maduros para desarrollar una conciencia nacional, un colectivo que asumiera a todos como iguales, como ciudadanos sin diferencias. 4

En consecuencia, dada las circunstancias, al inicio de la independencia debimos apostar por el proyecto monárquico de San Martín,5 el cual hubiera creado las condiciones que nos habrían permitido asumir plenamente el sistema liberal. Empero, en su contra se alzó la voz de los que defendían el republicanismo. ${ }^{6}$ De ahí que gente como Sánchez Carrión, Luna Pizarro y los que los acompañaron en el partido republicano, desarrollaron un sentimiento autonomista. 7

Esto dio lugar a un debate entre ambas posturas, venciendo en ese sentido los últimos, gracias a la deposición del ministro Bernardo Monteagudo y el triunfo oratorio en el debate de la

\footnotetext{
2 Entrevista a Carlos Contreras. En: Tiempos No. 5, Lima-noviembre 2010, 114.

3 Ello explica la casi inexistencia de un verdadero compromiso con la independencia (Anna 2003, 282). Lo cual se manifestó en una actitud diletante de los criollos peruanos frente a este proceso.

4 Entrevista a Manuel Burga. En: El Comercio, 1-ago-2005, A8.

5 Entrevista a Hugo Neyra. En: Correo, 28-jun-2003, 12-13.

${ }^{6}$ Cecilia Méndez considera que los efectos de las cortes de Cádiz entre los diversos sectores sociales, favoreció la formación de la república, incluso con la contribución de los grupos campesinos monárquicos (como los de Iquicha en Ayacucho) (Méndez 2014, Cap. IV).

7 Entrevista a C. Contreras (Tiempos No. 5,117 ).
} 
ISSN: 2710-0499 ISSN-L: 2710-0480

Sociedad Patriótica. ${ }^{8}$ Luego, al retirarse San Martín del Perú en 1822, quedaron dueños de la situación, puesto que dominaron el Congreso Constituyente (Basadre I, 2005, 38). ${ }^{9}$ En este contexto, Waldemar Espinoza considera que se escogió para nuestro país el modelo liberalburgués, copiado de las revoluciones norteamericana y francesa. Lo que, en definitiva, al ser un diseño manejado sin estudios previos de la realidad peruana, resultó en un rotundo fracaso (Espinoza 2009, 91). Idea con la que también concuerda Alberto Flores Galindo, quien señalaba que el liberalismo y la democracia, con los que pretendió reemplazarse el orden colonial, fueron inviables (Flores Galindo 1991, 181).

Lo que revela, a juzgar por la mesurada reflexión de Jorge Basadre, que nuestro país prefirió con osadía seguir el riesgoso camino de la República, ${ }^{10}$ vetando enérgicamente la prudente fórmula monárquica (Basadre 1973, 165); decisión en la que pesó decididamente, la presión ejercida por los criollos de Lima, respaldados por los pensadores hispanoamericanos. ${ }^{11} \mathrm{En}$ estas condiciones, los planes monárquicos se quedaron en el marco de las intenciones no maduradas en la realidad. San Martín pensó honestamente, que esta fórmula intermedia entre la anarquía y el despotismo (constituido por la monarquía constitucional), era una solución a las carencias con que iniciamos nuestro camino a la independencia (Basadre I, 2005, 43).

Sin embargo, la porfiada insistencia en adoptar el sistema de gobierno republicano, fue un terreno que produjo una serie de dificultades para la instauración de los principios, instituciones y prácticas del liberalismo político. La cual hubo de encontrar resistencias y obstáculos, debido a la persistencia de ideas, tradiciones institucionales y jerarquías políticas propias del Antiguo régimen colonial (Sábato 2006, 264).

El paso del tiempo parece haberle dado la razón al 'santo de la espada'. No estábamos preparados para un sistema republicano. ${ }^{12}$ En cuyo caso, el proyecto sanmartiniano nos

\footnotetext{
${ }^{8}$ Una buena descripción de la polémica entre los monarquistas y republicanos, puede verse en Contreras y Cueto (2000, 54 y ss.).

9 No obstante, según da cuenta Waldemar Espinoza (2009, 89), la conveniencia de una monarquía constitucional, quedó definitivamente desestimada cuando José de la Riva Agüero, que combatía a los liberales y protagonizó el motín de Balconcillo (27 de febrero de 1823), por falta de carácter y estrategia militar, perdió la última oportunidad para erigir en el Perú este proyecto.

${ }^{10}$ Hilda Sábato sostiene que la adopción del sistema republicano, es una característica de la historia política de las Américas del siglo XIX. De esta manera, dice ella, se convirtieron en un campo de experimentación política, donde ideas provenientes de Europa fueron adoptadas y adaptadas en un territorio vasto y heterogéneo (Sábato 2006, 263).

${ }^{11}$ No obstante, hasta cierto punto el republicanismo nos fue impuesto por el resto de países de América Latina. En este orden seguimos la corriente política del resto de países, e incluso si en el Perú hubiese habido una mayor popularidad de la monarquía constitucional, esta no habría sido viable por el recelo de nuestros vecinos, ya que estos hubieran recelado de una monarquía en medio de repúblicas, de manera que habría existido un rechazo muy fuerte de parte de los países colindantes (Espinoza 2009). Derrotero que también estuvo inmerso dentro de la influencia desplegada por los EE.UU., como parte de la política trazada por su presidente James Monroe en 1823, y sintetizada en la frase "América para los americanos". Doctrina que, bajo el pretexto de la defensa de los procesos independentistas de los países sudamericanos, en los hechos ampliaba la frontera de injerencia de la Casa Blanca en el subcontinente (Doctrina Monroe).

${ }^{12}$ En opinión de Espinoza $(2009,96)$ y otros historiadores que han estudiado este tema, el germen del porqué el Perú republicano del s. XIX y aún del XX iba a tener una vida inquieta y desordenada, se debe a que el Perú 
hubiera permitido ir creando una cultura democrática. ${ }^{13}$ Lamentablemente, su incomprensión generó que la sociedad peruana naciese arrastrando una serie de lastres desde su momento fundacional. En ese sentido, su nacimiento no significó la cancelación del pasado, sino sólo la prolongación del Antiguo régimen colonial, revestido en las formalidades de un Estado moderno.

\subsection{La república: jurada mas no amada}

Algo que no se quiere, no se siente, ni se vive, sólo se acepta por inercia. Como resultado de ello, la élite dominante no tuvo ninguna intención de que esto florezca como república. Es más, las élites peruanas, las más conservadoras de América (en lo económico, político y social), se opusieron hasta el final a la independencia (Gootenberg 1989, 30)

Este accionar existente desde el virreinato y que iba de la mano con una praxis económica y política, cuando llega la república se transforma, porque quienes se encargaron de hacer la independencia, recrearon las ideas liberales para que el viejo sistema colonial siga funcionando. Por eso es que, sobre esta base, las instituciones liberales no prosperaron. A causa de ello, devino la formación de un régimen caracterizado por la ausencia de ciudadanía (Escalante 1993; Chiaramonte 2004, Cap. III), el reacomodo de las élites a la nueva situación, el surgimiento de insólitas formas políticas y la instauración de un Estado empírico.

En cuanto a lo primero, el principal problema para la instauración de la república es que deben existir cuerpos políticos diferentes a los del antiguo régimen. En el caso de nuestro país, el nuevo sistema tuvo que luchar contra la indiferencia de las personas frente a los asuntos públicos, puesto que -como en los tiempos de vigencia de la monarquía hispanasubsistía la despreocupación de las gentes por la cosa pública. De allí que, para la organización republicana que tenía como requisito la existencia de una comunidad política de individuos ciudadanos, con la condición de hombre libre, propietario y educado, se le planteó una dificultad porque éstos eran una minoría. ${ }^{14}$

En tales circunstancias, Osmar Gonzáles y Martha García (1987, 10), estiman que el fracaso de la independencia criolla puede ser resumido en que ésta consiguió la victoria militar, pero no logró hacer de sus habitantes "ciudadanos peruanos". ${ }^{15}$ Observación ya planteada por Basadre cuando reclamaba la "promesa de la vida peruana”. De suerte que, entre caudillos y masa, criollos y pueblo, intelectuales e indios, negros y mestizos, aristócratas y plebeyos, etc.

se liberó del dominio español antes de tiempo. Debió esperar y hacerlo por lo menos 80 ó tal vez 100 años más tarde, entre 1904 a 1920, décadas en la que recién la clase dominante habría estado preparada para asumir los roles de efectivos planificadores y de excelentes administradores.

${ }_{13}$ Entrevista a Hugo Neyra. En: Correo, 28-jun-2003, 13.

14 En términos porcentuales, Javier Pérez señala que más del 90\% de la población era indígena y analfabeta; mientras que el porcentaje de propietarios o no dependientes era muy bajo (Pérez 2008, 132).

${ }^{15}$ Esto se sintetiza en una frase de Juan Carlos Huaraj $(2010,135)$, "la fidelidad al rey se sincretizó en una lealtad al supremo Estado independiente". Sincretismo inicialmente detectado por Basadre $(1994,2)$, quien constata que los valores absolutos antes acatados en los conceptos de rey o religión, fueron transferidos con igual dogmatismo a los conceptos de patria y libertad. 
no existió la condición política que les permitiera verse como iguales en la sociedad. Patentizando en los hechos, que la prédica democrática y liberal sólo encarnó en un pequeño grupo privilegiado, que mantuvo las inequidades y asimetrías con las grandes mayorías.

Sobre el segundo punto, Juan José Vega sostiene que, con la iniciación de nuestra vida independiente, lo que se formó fue una "república virreinal". En la que la aristocracia colonial habría así de conservar sus privilegios económicos virreinales, aunque tuviese que ceder parte de su sitio a los nuevos grupos medios (Vega 1994, 5). En tal sentido, la gesta independentista de 1821, no fue más que el proyecto de un grupo social con intereses propios, que sólo cambio el carácter de la dominación. ${ }^{16}$ Quedó atrás la colonia, pero la independencia no reportó nada nuevo a la naciente república (Freyre 1987, 4).

Este punto de vista, queda probado por Paul Gootenberg, quien confirma que la élite peruana, al momento de producirse la independencia, carecía de proyectos nacionalistas o liberales viables (Gootenberg 1989, 33). Por lo que la independencia, al ser promovida y usufructuada por los criollos, no representó el advenimiento de una nueva clase dirigente.

Direccionamiento que se explica en razón de que los criollos peruanos fueron mayoritariamente hispanófilos, pero tuvieron que asumir comportamientos "independentistas", debido a la coyuntura de entonces, generada por la presencia de la corriente libertadora del sur liderada por el general San Martín (Lora 1988, 89). En este curso, la república luego de la proclamación sanmartiniana, constituyó un reacomodo de la aristocracia colonial a las nuevas condiciones. En vista que con la independencia se rompe con el dominio español, pero no así con el sistema económico virreinal, ya que los criollos que participaron en ella, eran en gran medida terratenientes, inmersos dentro del circuito de una economía rentista.

Por tanto, debido al peso de esta inclinación, la élite criolla poco hizo para que el Estado tratara de crear patria para todos. Con la independencia surgió un país con un revestimiento burgués o liberal, en el cual pocos creyeron de verdad. De manera que, la vida cívica conformó una ficción para las grandes mayorías (Vega 1994). Cubierta que a los criollos, bajo la apariencia de ser una burguesía republicana, les habría de servir para mantener en la república sus fueros y privilegios.

En tercer término, dada las peculiaridades señaladas, la fundación de este régimen sin ciudadanos, ante la salida de la sólida administración española, que deja al país sin una élite y sin que nadie recoja el poder (Favre 1969, 92), generó la formación de formas políticas extrañas, como resultado de implantar un sistema republicano en ese contexto de antiguo régimen. Lo que explica, en función de la disyuntiva planteada, la manifestación del caciquismo político (caudillismo), el cual podía ser una autoridad, un hacendado, un militar

${ }^{16}$ Esta impresión ha sido corroborada en el trabajo de Timothy Anna (2003, Cap. I), quien establece que el proceso de independencia es la historia de una minoría sobreprivilegiada, que actúo de acuerdo al más puro oportunismo. 
o todas estas cosas (Sobrevilla 2019, Cap. III). Este sistema político, en palabras de Cristóbal Aljovín, puede ser definido como un régimen basado en la voluntad del líder, quien accede al poder usando la fuerza (Aljovín 2000, 39).

Desde esta mirada, a consecuencia de la falta de una burguesía orgánica, en los primeros tiempos de la independencia el poder estuvo a merced de estos actores políticos, principalmente militares. Quienes, por su misma formación castrense como hombres de guerra, no poseían las credenciales adecuadas para dirigir un trabajo de reconstrucción económica. En vista que al constituir el producto natural de un período que no había logrado crear una nueva clase dirigente, muy pronto se convirtieron en un azote causante de inestabilidad institucional (Espinoza 2000, 95).17 Esto, debido a los continuos enfrentamientos y guerras civiles que surgieron entre ellos.

En cuarto y último lugar, a raíz de todo esto, las investigaciones realizadas por Basadre (1973, 250 y ss.) nos revelan aspectos que conviene destacar, en el sentido de que, en nuestra patria, el sufragio panacea de la democracia liberal, no funciono con efectividad, o funcionó con intermitencia, o funcionó mal. $\mathrm{O}$, a veces, tuvo resultados conflictivos. El mismo autor señala que en las instituciones que mediante él se establecieron, surgieron características de enfermedad que el tiempo no curó sino hizo crecer. El Poder Ejecutivo osciló frecuentemente entre el abuso y la debilidad. El Poder Legislativo, acentúo su afán de interferir en la administración pública y de aprobar leyes empíricas o movidas por minúsculos e impuros intereses. La burocracia quedó a merced de las contingencias políticas y, en general, existió una baja remuneración para los trabajadores del Estado. En suma, el Estado peruano fue y continúo siendo un Estado empírico, al que se le agregó el abismo social.

La correlación de estos factores determinó, que la sociedad peruana de la primera generación republicana, se constituya como una república a medias, un algo que está en una constante duda. A causa de ello, el Perú después de la guerra se convirtió en una corporación desorientada en su rumbo, que en último término tenía una confusión con su identidad.

\section{La constitución de la idea de nación en el Perú independiente.}

La nación como idea surge en el siglo XVIII, emanado de unos orígenes, religión, lengua e intereses comunes del que emergerá el concepto de nación-Estado, sobre el cual se han constituido como tales la mayor parte de las naciones modernas. En ellas, el compromiso con la idea de la libertad individual y la existencia de un gobierno representativo, se convirtió, gracias a la preponderancia del 'siglo de las luces', en el derecho natural de todo individuo (Hegel: La fenomenología del espíritu).

En Europa, el gran punto de apoyo de esta idea fue la revolución francesa, cuyo espíritu derivado de la ilustración se impregnó en América en los ideales de libertad e independencia

${ }_{17}$ Esta impresión ha sido anteriormente corroborada en el trabajo de Paul Gootenberg (1989, 33 y ss.), dedicado a examinar la formación económica del Perú republicano en sus cuatro primeras décadas de vida independiente.

Revista Revoluciones -61- Vol. 3, No 5 (2021), pp. 54-72

Esta obra está bajo una licencia internacional Creative Commons Atribución 4.o. 
ISSN: 2710-0499 ISSN-L: 2710-0480

que guiaron sus respectivos procesos independentistas. Es así como en el primer tercio del siglo XIX, entre 1810-1830, dentro del continente americano fueron surgiendo nuevos países que, tras pérdidas territoriales y cambios de nombre, han quedado organizados como son en la actualidad.

Empero, este modelo que fue importado del Viejo Mundo, no tuvo en cada uno de los países de América la misma intensidad, pues adquirió una mayor maduración en las regiones periféricas, como Argentina o Chile, por ejemplo, pero en el Perú, que era el núcleo de la dominación española, le faltó dicha madurez. El resultado será la conformación, al comenzar el siglo XIX, de un débil Estado de derecho impuesto en un medio colonial.

\subsection{Planteamiento teórico-político constitutivo de la nación en el proceso histórico peruano}

El esfuerzo por sustituir la idea de nación-pueblo (inserta en la idea de nación colonial), por una nueva nomenclatura política (nación-Estado), plantea en su conformación el desarrollo de una concepción voluntarista, llamada también francesa o jacobina, según la cual, en oposición a la concepción historicista ${ }^{18}$-desarrollada inicialmente en Alemania-, es el Estado el que configura la nación en virtud de medidas unificadoras, idiomáticas, fiscales, territoriales, ideológicas, etc. De manera que, en razón de esta orientación, es el Estado como organismo político el que precede a la nación (Benito 1986, 238).

En nuestro caso, como seguidores de esta tradición, hemos propendido a la estructuración de un Estado de tipo unificado regido por un solo gobierno, cuyo poder se extiende a todo el territorio y a todos los ciudadanos, sometidos en él a un mismo entramado de derechos y deberes (Benito 1986). Sin embargo, como consecuencia de la larga permanencia del poder español y la sacralización de todas las formas del dominio colonial (Lazo 2004, 203), las nuevas ideas racionalistas y liberales de entonces fueron readaptadas con el único fin de adoptar la formalidad de una nación-Estado, que contradiciendo los preceptos liberales, se distinguió por la ausencia de ciudadanía.

De este modo, la sustentación doctrinal como unidad y síntesis de lo diverso, cuya unidad radica en la conciencia de libertad que tienen todos los hombres que forman la nación (Rousseau: El contrato social), no fue operativa en nuestra realidad, porque fuimos compelidos a una unión e identificación simulada, obtenido sobre la base de cambios aparenciales. Lo que reafirmó, de acuerdo con Carlos Lazo y Alex Ortegal, la permanencia de la heterogeneidad social en la que la libertad egocéntrica de unos ejercida a costa de la no libertad de los demás, siguió siendo una constante (Lazo y Ortegal 1999, 5).

\footnotetext{
${ }^{18}$ En esta concepción, la nación es una comunidad unida por una serie de aspectos compartidos, como pueden ser el idioma, las tradiciones culturales, el grupo étnico, etc. Pero el elemento fundamental de cohesión sería una solidaridad de «sentirse nación», que proveniente de generaciones anteriores, se prolonga a lo largo del tiempo y se proyecta hacia el futuro de acuerdo con lo que el filósofo alemán Johann Gottfried von Herder (17441803) llamó «el espíritu de los pueblos». Así pues, en esta concepción, la nación es anterior al Estado (Benito 1986).
} 
Conforme con ello, la sociedad peruana republicana constituida en el siglo XIX, al conservar ciertos elementos propios de una sociedad de antiguo régimen (síntesis social respaldada en una diversidad corporativa), mantuvo subrepticiamente la idea de nación-pueblo dentro de la figura de nación- Estado. Fórmula atípica sostenida en una pseudo fraternidad, que, a través de un Estado gerencial, sostuvo una identidad y cohesión impuesta.

\subsection{Unidad sin identidad: ¿firme y feliz por la unión?}

En contraposición a una precedente experiencia y práctica burguesa de cimentación capitalista, la sociedad peruana decimonónica, acogió la formalidad de una nación-Estado, y al hacerlo eludió el requisito de contar con la existencia de una comunidad de individuos ciudadanos, reemplazándola por una ciudadanía virtual o imaginaria, como la denomina Escalante. El resultado fue como lo testimonia Charles Milner, cónsul británico en Lima en 1826, que "el gobierno es consciente de que el Estado sufre por la ignorancia e indolencia de la población, [...]" (Bonilla I, 1975, 52). En este sentido, este testigo de excepción, confirma que la naciente república tuvo que luchar contra la indiferencia de las personas frente a los asuntos públicos. Lo cual revela las limitaciones y debilidad de nuestra élite, quienes fueron incapaces de materializar un proyecto nacional que aglutine a todos los ciudadanos en torno a un objetivo común, en razón de su imposibilidad de transformar y cancelar las supervivencias del antiguo régimen (Lora 1988, 128).

Por lo tanto, al generarse una unidad sin identidad, la frase 'Firme y feliz por la unión' que aparece en las monedas de 1825, no fue más que un recurso que se utilizó para ocultar la despreocupación de la población por la cosa pública, ante un sistema en el que no se sentían representados y que los mantuvo al margen en el ejercicio de sus derechos y libertades, no otorgándoles siquiera la categoría de ciudadanos, por ser éstos ajenos a la condición de ser hombres libres, propietarios y con educación. Entonces, en esta ficción de Estado moderno, nuestro país no se erige como nación, porque careció de una burguesía nacionalista que construyera una patria para todos en base a un proyecto a futuro (Basadre 2005, 148), como referente de identidad y unidad.

Por lo mismo, la aristocracia limeña, fundadora de la patria, no fue capaz de transformarse en una burguesía creadora; y, por ende, en una clase dirigente. En este entendimiento, según las reflexiones de Nelson Manrique, estamos hablando de una élite que no le interesó crear una identidad nacional, ni edificar los referentes que le permitieran presentar sus propios intereses, como el conjunto de intereses de la nación, ${ }^{19}$ y que, por el contrario, ahondo las brechas sociales en la que se hizo improbable el poder adquirir una identidad firme y relativamente unitaria.

\section{Entre el autismo y la indefinición. El paradójico vaivén de una élite sin horizontes}

${ }_{19}$ Entrevista a Nelson Manrique. Al día con Hildebrandt. 6-oct-2006. 
Como se ha venido señalando líneas más arriba la constitución de nuestra vida republicana, después de la gesta de la independencia, nos demuestra en su curso histórico, que este esfuerzo no logró una plena concreción dentro del conjunto de la sociedad y sus instituciones, debido a que su construcción se hizo sobre la base de un mosaico, cuyos pedazos y retazos no consiguieron amalgamarse en un todo. En este sentido, el régimen que surge como parte de este proceso, al no estar constituido por grupos sociales con absoluta conciencia de su ser en sí y para sí, puso de manifiesto sus limitaciones.

Esta debilidad, en nuestro caso, admitió que las élites actuasen de espaldas al rol histórico que debieron asumir, orientando su accionar únicamente a aislarse en sí mismos y priorizar la defensa de sus intereses. Es por eso que este apartado, tiene por intención dar a conocer cómo esta circunstancia, fruto de la falla estructural con la que nacimos, ha afectado el funcionamiento de nuestro sistema republicano, el cual, desde la instauración de esta primera república, no ha logrado delinear las bases que le permitan renovarse constantemente para mejorar el destino de las generaciones venideras. Hecho que mina nuestro devenir, impidiendo que nos constituyamos en una nación con una identidad robusta, un sistema político inclusivo y participativo maduro y, asimismo, sin una abismal polarización social.

\subsection{Política sin horizonte: la inexistencia de un proyecto nacional}

La política como conducción de la vida, es el instrumento ejecutivo que, a través de la formalización de un orden y su correspondiente conservación, tiene por finalidad la búsqueda y conservación del bien público (Palza 2008, 220-221). Pero ésta en el Perú, tiene la particularidad de haberse convertido en parte del concepto de inestabilidad; en la que, si volvemos la mirada a la gestación de la república, como fundamenta Carmen Mc Evoy, veremos una política de la peor especie, ${ }^{20}$ tiznada por una serie de antivalores que congénitamente se trasladan del virreinato a la república. La permanencia de esta tradición malsana tuvo un efecto negativo en nuestra sociedad, puesto que tendió a anularla como tal.

Esta visión tuvo en el siglo XIX sus respectivas expresiones. Vislumbrando este acontecer en la década anterior de la independencia, un autor anónimo en un trabajo titulado Manual de un republicano (Philadelphia 1812), establecía que el republicanismo "que se intenta en América, tendrá una buena aceptación entre todos los ciudadanos, [...] siempre que no estén sujetos a una ceguera incurable [...]". Con el mismo espíritu, el limeño Riva Agüero en su libro Manifestación histórica y política de la revolución de la América (Bs. As. 1818) reparaba que "sin la observancia de las leyes no puede haber estado ni asociación política".

La trascendencia a nuestra época de estas y otras reflexiones, recogidas en la literatura historiográfica, confirman que detrás de la euforia liberal del primer decenio de la independencia, se ocultó la continuidad esencial de las ideas y actitudes

${ }^{20}$ Entrevista a Carmen Mc Evoy. 'Al día con Hildebrandt'. 12-dic-2007. 
contrarrevolucionarias. ${ }^{21}$ Concluyendo que, en medio de la intensidad de este conflicto, se reveló la gran fragilidad de las recién establecidas formas constitucionales de gobierno, cuyo modelo era la ideología liberal (Hamnett 1978, 379). ${ }^{22}$

El incumplimiento de estos principios, de acuerdo con Jorge Basadre, fue fruto de que el Perú al carecer de tradiciones de gobierno parlamentario y afrontar una serie de graves problemas de estructura social, económica y racial, no hizo posible que las nuevas entidades representativas logren enraizar sanamente en él. Como consecuencia de este hecho, según sus observaciones, estas instituciones con el tiempo se enviciaron y fueron los mejores instrumentos para interferir en la vida política del país (Basadre 1973, 247).

En este sentido, la endeblez de los ideales republicanos, incapaces de apuntalar nuestra naciente vida independiente, consintieron la configuración de una incipiente república que actúo sólo dentro de ciertos parámetros formales, lo que dio por resultado una practicidad anómala, en el que los gobiernos se movieron en beneficio de las élites y de intereses extranjeros, en desmedro de los grupos mayoritarios, quienes fueron los más perjudicados en su bienestar. Argumentación que, salvando las distancias, trae a colación Eugéne de Sartiges, viajero galo que vivió en el Perú, para el cual la independencia no fue hecha por el pueblo ni lo había favorecido (citado por Macera 1976, 116). En estas condiciones, los mecanismos que proporcionó el sistema sirvieron -muchas veces-, para que diversas administraciones, como entes corporativos, mediante pactos implícitos y tratos con los grupos de poder económico interno y externo, llegasen al Estado para beneficiarse de él, en virtud de estas alianzas.

Esta flaqueza hizo inviable una planificación que tuviese como mira la construcción de una nomenclatura política que liquide las taras del pasado. Tendencia que también es resaltada por Basadre, para quien la abolición de los títulos de nobleza y la implantación de la república conquistados por los liberales en el Perú durante su primera etapa de predominio (1822-23), fue insuficiente, ya que éstas -en el análisis del mismo autor-, no estuvieron acompañadas por otros cambios en el sistema vigente (Basadre 1973, 235).

De modo que esta patente realidad impuesta en el siglo XIX, descubre que el régimen que brota y sobreviene como resultado de este despliegue, no es más que un malogrado proyecto,

${ }^{21}$ Por ejemplo, el 9 de octubre de 1820 , se realiza una Junta del Consulado de Lima, en el que se acuerda como punto único de la agenda "se trate y proponga únicamente la acumulación de un fondo de Quinientos mil pesos [...] para premiar las acciones meritorias y heroycas que verifican nuestros soldados y defensores en los combates [...] que tubieron con los caudillos Sn. Martin y Cochrane, por mar o tierra hasta exterminarlos o auyentarlos de este territorio" (AGN. Tbnal del Consulado, Adm., Juntas de Comercio, Cj. 3, 1728-1821, Exp. 1, fol. 1). En dicha reunión participa Francisco Javier de Izcue, ex cónsul del Tribunal del Consulado entre 1813 y 1816 (Flores Galindo 1991, 197), quien es uno de los firmantes de este petitorio. Este personaje es el mismo que a la postre, el 15 de julio de 1821, aparece rubricando el Acta del Cabildo de Lima pronunciándose a favor de la independencia del Perú. Posteriormente este comerciante emigró a España en 1822 (Flores Galindo 1991, 203). Así como él, existieron otros objetores furibundos del proceso independentista, que por conveniencia terminaron aceptándola como una medida de supervivencia política y económica.

${ }^{22}$ Explicando la dificultad en el arraigo de los ideales republicanos, Bernardo de Monteagudo en su Memoria sobre los principios políticos... (Quito, 1823) aseveró que "la ciencia que enseña los derechos y obligaciones sociales es vasta y complicada: ella exige un largo proceso de aprendizaje, y la historia de todos los pueblos sin exceptuar uno solo, demuestra, que en nada es más lenta la marcha del género humano, como en el conocimiento práctico del término de las relaciones que unen a los gobiernos y a sus súbditos". 
cuyo propósito se echó a perder a consecuencia del nacimiento que tuvimos. No es extraño, por lo tanto, que la rectoría y vigencia de este lineamiento se haya institucionalizado en todos los órdenes de la vida social. Esto significa, que los preceptos republicanos al estar faltos de un eficiente soporte, no consiguieron modificar el orden estructural, mediatizando los cambios coyunturales solo a cambios volátiles que no transformaron la esencia y la fuerza de esta estructura.

En tales circunstancias, Manuel Burga afirma que, a causa de ello, arrastramos el proyecto incompleto de la fundación de la república compuesta por ciudadanos, donde las únicas diferencias sean la geografía o las identidades regionales. De manera que esto, que es más acentuado en el Perú que en América Latina, no ha logrado que nos constituyamos como una nación moderna. ${ }^{23}$ Es por ese motivo que nuestra inaugural vida republicana, no es más que una rehechura adaptativa de un vacilante espíritu republicano que no encontró vías seguras de ejecución. Rasgo peculiar que deja ver las barreras y debilidades de los grupos de élite, quienes fueron incapaces de materializar un proyecto nacional que aglutinase a todos los grupos sociales en un objetivo común, connotando tan solo una realidad política movilizada a su favor.

Esta imposibilidad de unirnos en una aspiración colectiva, principal problema en la obra de Basadre, es en definitiva nuestro cardinal dilema histórico y es, por consiguiente, lo que mata al Perú. De manera que ello conlleva a la inexistencia de una élite organizada con un plan, y, por ende, el de una clase dirigente que sea capaz de presentar sus intereses particulares como los intereses de todos. ${ }^{24}$ En esta perspectiva, los criollos limeños no supieron nacionalizarse y asumir este territorio como suyo y a la población como próxima y sin diferencias. Por ello no le interesó desarrollar un proyecto nacional, porque simplemente no hubo ninguna visión ni proyección a largo plazo, sino más bien un enfoque cortoplacista, ganado siempre por las circunstancias.

\subsection{Autismo económico: centralización del aislamiento y defensa de granjerías}

Como se ha señalado, lejos de trazar una política con un cierto horizonte, la élite dominante manejo el naciente Estado peruano en función a sus intereses. De modo que, su preocupación giró principalmente en velar por la defensa de sus beneficios, prebendas y granjerías, para lo cual contaron con operadores políticos y económicos que se encargaron de mantener el modelo económico que los benefició. Así lo advirtió el viajero francés Rattier de Sauvignan, quien señaló que "la protección y la intriga influyen más que el mérito en la distribución de los cargos de Estado" (citado por Macera 1976, 93).

En esta dirección la seria reflexión de Fritz Wills resalta esta idea, indicando que desde la independencia, el Perú al no constituirse como un Estado soberano o relativamente autónomo, con una autoridad central viable, desarrolló un imitación de desarrollo liberal,

23 Entrevista a Manuel Burga. El Comercio.1-ago-2005.

${ }^{24}$ Entrevista a Nelson Manrique. 'Al día con Hildebrandt'. 6-oct-2006. 
una "sociedad sin techo". Una sociedad, como él lo señala, marcado por: un Estado débil, un alto grado de privatización del poder público y un proceso acumulativo de penetración extranjera (Wills 1979, 36).

La preeminencia de este orden, que como consecuencia de este hecho devino en un fracaso de las instituciones del nuevo Estado, en proponer una alternativa viable en reemplazo de la autoridad española (Wills 1979, 50). Tuvo por excepción, en la visión de esta tesis, dos esfuerzos por cerrar el techo e imponer un control sobre los grupos de poder peruano y extranjeros, conformados por el régimen de Castilla (1845-51) y (1855-62) y el período del guano y el salitre (1840-83). Lapsos en que pareció que estos esfuerzos lograrían cerrar el techo con el surgimiento de un Estado verosímil, pero todo fue en vano, porque la sociedad sin techo continuó (Wills 1979, 52).

Esta tendencia explica la fragilización económica del liberalismo y el auge del proteccionismo, durante las primeras décadas republicanas; lo que significa que el Perú era liberal en lo político pero proteccionista en lo económico. ${ }^{25}$ Un testimonio ilustrativo de esta disposición fue referido por el cónsul británico en Lima, Belford Wilson, en su informe del 15 de enero de 1834, en donde califica de antiliberal el sistema de comercio del Perú. Según este funcionario, la causa principal de esta postura se debe a que "tan ignorante es el país de las ventajas que se pueden derivar de ampliación y firmeza del tráfico comercial [...], a la cual ha sido arrastrado por la ignorancia egoísta de sus gobernantes y por su propia imbecilidad" (Bonilla I, 1975, 88). Así concluye que "en el Perú existen [...] puntos de vista menos liberales y honestos, que en ningún otro país de América Hispánica” (Bonilla I, 1975, 104). La razón de este contrasentido, es que las élites comerciales y la de hacendados, como en los tiempos coloniales, trataban de mantener incólumes sus intereses a través del manejo del monopolio; en el que el poder fue un eficiente martillo de hierro, que se utilizó para tales propósitos.

El patrocinio de esta realidad se patentiza en el hecho de que, si bien los miembros de este grupo difuso no poseían un perfil claro en relación al manejo o conducción política del Estado, si lo tenían en cuanto a factores o circunstancias que pudieran resentir y alterar sus prerrogativas.

Esta actitud que se trasluce a nuestro tiempo, a través de los estudios especializados, manifiestan la praxis inequívoca de esta conducta, que en este caso se revela en el análisis realizado por Hamnett, quien distingue que tras los meses transcurridos entre la partida de San Martín y la llegada de Sucre, se puso en evidencia que la aristocracia peruana era incapaz de gobernar, lo que le permitió a Bolívar llegar rápidamente a la conclusión de que la élite limeña era tan indiferente a las fuerzas de liberación argentino-chilenas como a las fuerzas realistas en la sierra. Por esta causa, estos notables al llamar a Bolívar al Perú, sencillamente esperaban poderlo usar como peón en su estrategia para conservar sus privilegios, librándose de dos poderosos ejércitos al mismo tiempo (Hamnett 1978, 353).

25 Para una percepción cuantitativa de los vaivenes entre el liberalismo y proteccionismo, véase el cuadro citado por Contreras y Cueto $(2000,97)$, que ofrece un indicio testimonial de lo expresado.

Revista Revoluciones -67- Vol. 3, No 5 (2021), pp. 54-72 
Este oportunismo que es recurrente en nuestra vida republicana, constituye la genética que dará comienzo - como observa Basadre-, al desorden político, el abismo social y el despilfarro económico decimonónico, que convirtieron en endeble a un país exuberante en riquezas. Actitud que hizo inviable al Perú, porque las ganancias de sus actividades económicas no se tradujeron en una capitalización de la producción. Transformación que vuelve a esta primera república en un sistema inverosímil.

Como se ve, nada ilustra más vivamente la implicancia dañosa de este despropósito, el cual tuvo por intención la usurpación y sometimiento de la república para favorecer los intereses de este grupo monopólico. Grupo que posteriormente, incluyó a los inmigrantes extranjeros y a los peruanos, a los terratenientes costeños y a la burguesía urbana, quienes se convirtieron en propietarios de haciendas (Wills 1979, 54). ${ }^{26}$ Situación que les concedió a estos emigrantes foráneos y sus descendientes alcanzar posiciones muy estratégicas, a través de sus vinculaciones con la élite limeña (Wills 1979, 88).27

En virtud de esta heterogeneidad la aristocracia devenida en oligarquía funcionó como el portavoz local de los intereses extranjeros, a los cuales estaba atada por sociedades conjuntas y una identificación cosmopolita antes que peruana (Wills 1979, 55). Destacando esta condición, Paul Gootenberg señala que estas camarillas jamás dieron muestra en el Perú de nacionalismo económico. Tales grupos, agrega, se ofrecieron gustosos a satisfacer las necesidades del capitalismo noratlántico y a procurarle ganancia sobre ganancia; sometiéndose a la coacción que se les imponía, a costa de intereses nacionales de largo plazo y mayor alcance. Lo cual se yergue como el primer signo de la secular herencia antinacional de las élites republicanas (Gootenberg 1989, 29).

Esto significa que a esta minoría rectora no le importaba entregar nuestra soberanía económica a las potencias extranjeras, con tal de conservar sus ventajas personales, familiares y dinásticas (Drassinower 1980, 107). Lo que revela que estos grupos de élite no obedecen al interés nacional, sino que lo aparentan para ocultar su rol de intermediarios y apéndices locales de poderes externos. Naturaleza que configura así la mentalidad histórica de esta clase, caracterizada por sus metas económicas excluyentes y su gustosa subordinación a intereses extranjeros.

\subsection{Atavismos dañosos e inexistencia de nación}

A la clase dominante criolla ligada a atavismos, que son tradiciones malsanas que constituyen un lastre a ser superado, le faltó una actitud autocrítica a partir del ejercicio de una libertad negativa, mediante la cual reconociera y tomase conciencia de sus actitudes dañosas y

\footnotetext{
${ }^{26}$ Véase sobre ello el trabajo de Reyes (1998). Investigación en el que el autor explica cómo un conjunto de familias sin ascendiente colonial, a partir de 1830 copa las propiedades rurales y se diversifica desde 1860 hacia otros sectores productivos. Cita para el caso ejemplos como Derteano, Elías, Montero, Laos, Ramos, Álvarez Calderón, Sevilla, entre otros.

${ }^{27}$ Sobre este punto véase también a Yepes (1972, Cap. IV), para una visión de la actividad de los inmigrantes extranjeros que llegan al Perú entre fines de la primera y última mitad del siglo XIX.
} 
perjudiciales, para plantear nuevas condiciones de vida a través de un camino alterno. Sin embargo, esta élite está orientada fundamentalmente a conservar la tradición, y a una vida dispendiosa, con adhesión a culturas foráneas en lugar de integrarse al progreso nacional (Drassinower 1980, 109).

Este extrañamiento, característico de esta élite, constituye la mejor muestra de la vigencia dentro de ella del lucimiento del status, la exhibición de un alto consumo y el alejamiento de un comportamiento acorde con la capitalización de la producción misma. Barrera que aísla a estos sectores del resto del país, ensimismándola en un mundo afirmatorio de una libertad egocéntrica, que vive de espaldas al Perú.

En esta medida, la aristocracia criolla de Lima al no adherir al país como suyo en el transcurso del tiempo histórico secular, no se ciñeron a la premisa resaltada por Riva Agüero, de que "el objeto de un Estado no puede ni debe ser otro que la felicidad pública", lo que le lleva a reflexionar sobre la perentoriedad de esta situación, en un ambiente completamente opuesto al mismo, al preguntarse "¿cómo podrá haberla, en donde se aplica todo el bien a la parte menor de la nación, y todo el mal a la parte mayor?” (Riva Agüero 1818). Esta objeción avista la asimetría instaurada por los colonos españoles y conservada por esta élite, en que se le hace ver que su papel es el de crear riqueza a partir de la riqueza y no pobreza para la mayoría, y riqueza para algunos.

Precisamente esta inequidad es lo que no ha permitido la existencia de una nación, que se consolide sobre la base de una comunidad de individuos libres unidos en torno a un proyecto común a futuro. En su lugar lo que existe es la prolongación y readaptación de la naciónpueblo colonial, bajo la forma de una nación-Estado liberal. ${ }^{28}$

Los cambios aparenciales producto de este barnizaje republicano, tema ampliamente estudiado por nuestra historiografía, ratifica que no tenemos una clase dirigente. Los miembros integrantes de este grupo creen serlo, y no lo son; por el contrario, son una clase que ha vivido siempre de los recursos que tiene el país, pero no obstante disponer de un gran poder económico, no ha sido capaz de construir una nación (Aquino 1987, 2).

La organicidad de la nación, opuesta a la experiencia histórica de las naciones europeas que se formaron primero y luego tomaron el Estado mediante una revolución social (Lazo y Morales 2003, 310), no es una vivencia operativa en nuestro caso. Ya que el Perú al adoptar la formalidad de una nación-Estado, que contrariando los principios liberales se caracterizó por la ausencia de ciudadanía, nos compelió a una unión e identificación simulada sostenida en una identidad y cohesión impuesta.

En esta medida, la justificación de este status quo, contempla la existencia de una identidad en la alienación, mediante la cual la conciencia autónoma del dominante se impuso sutilmente sobre la conciencia heterónoma dirigida del dominado, posibilitando el consenso

${ }^{28}$ Para una estimación más amplia del tema, véase a Lazo y Ortegal (1999) y asimismo a Palza (2008, 73 y ss.). 
y su extrañación (Lazo 1993, 89). Conforme a ello, el Perú asume la condición de una nación, principalmente porque nos une el pasado, no un presente, ni un proyecto de vida al futuro. En ese sentido somos «el ayer». Escenario en el que, al profundizarse las diferencias sociales, hizo imposible que este mosaico que somos, se galvanice y adquiera una unidad en la identidad.

\section{CONCLUSIONES}

Tal y como se puede observar en el desarrollo de este estudio, la larga duración del dominio hispano en el Perú y la sacralización de todas las formas de dominio colonial, hizo que tras la independencia se presenten una serie de incertidumbres e indefiniciones, que no permitieron afrontar el desafío de la institucionalización del nuevo Estado republicano. Este fenómeno, resultado de una independencia impuesta, al no ser capaz de reemplazar el Antiguo régimen con instituciones liberales, inviabilizó su cancelación, permitiendo su evolución bajo el revestimiento formal de un Estado moderno.

En consecuencia, como hemos insinuado, nuestro aprendizaje republicano fue difícil por dos motivos. Por un lado, no estábamos preparados, en razón de que no se habían generado instituciones democráticas de participación pública para la toma de decisiones en la vida política y económica. Por otro lado, el Estado republicano, al ser impuesto más que buscado, fue asumido por la élite criolla, obligada externamente a adoptar las formalidades republicanas, sin ninguna conciencia de lo que significa la libertad, la igualdad y la soberanía, reflejadas en el imperio de la ley en un Estado de derecho liberal.

El principal resultado es que, lejos de trazar una política con un cierto horizonte, la élite peruana oriento su accionar a privilegiar sus intereses. Mentalidad histórica definida por sus metas económicas excluyentes y su adhesión a intereses extranjeros. Atavismo dañoso afirmatorio de una libertad egocéntrica, que dificultó la organicidad de la nación conforme con una experiencia liberal republicana.

\section{AGRADECIMIENTOS}

A Luz Huertas Castillo, docente de la Fairleigh Dickinson University, New Jersey, EE.UU., Daniel Morán y Christian Rodríguez por sus valiosas recomendaciones y sugerencias.

\section{REFERENCIAS BIBLIOGRÁFICAS}

Aljovín, Cristóbal (2000), Caudillos y Constituciones. Perú: 1821-1845, Lima, PUCP-FCE. Anna, Thimoty (2003), La caída del gobierno español en el Perú. Lima, IEP. Anónimo (1812), Manual de un republicano para el uso de un pueblo libre, Philadelphia.

Revista Revoluciones $\mathbf{- 7 0}$ - Vol. 3, $\mathrm{N}^{\circ} 5$ (2021), pp. 54-72 
Anónimo (2019), «Doctrina Monroe». En: www.enciclopedia.us.es/index.php/ Doctrina_Monroe [Accesado el 8-jun-2019]

Aquino, Percy (1987). “Derecha peruana. Manipuladora, veleidosa y vacua”. Altavoz de domingo, $\mathrm{N}^{\circ}$ 51. Lima, 30-ago-1987, pp. 2-3.

Basadre, Jorge (1973), El azar en la historia y sus límites, Lima.

Basadre, Jorge (1980), La multitud la ciudad y el campo en la Historia del Perú, Lima, Ediciones Treintaitrés y Mosca Azul editores, 3ra edic.

Basadre, Jorge (1994), «La patria de 1821 a 1824». Gaceta Sanmarquina $\mathrm{N}^{\circ}$ 23, Lima, julio, pp. 2-3.

Basadre, Jorge (2005), Historia de la república del Perú, T. I. Lima, El Comercio, 8ava edic. Benito, Teresa et. al. (1986), La formación del Estado. Madrid, Cultural ediciones, 4ta edic.

Bonilla, Heraclio (ed.) (1975), Gran Bretaña y el Perú. Informes de los cónsules británicos: 1826-19oo T. I, Lima, IEP.

Contreras, Carlos y Marcos Cueto (2000), Historia del Perú contemporáneo, Lima, IEP.

Chiaramonte, José Carlos (2004), Nación y Estado en Iberoamérica, lenguaje político en tiempos de la independencia, Buenos Aires, Edit. Sudamericana.

Drassinower, Samuel (1980), Testimonio de una experiencia industrial peruana, Lima.

Escalante, Fernando (1993), República sin ciudadanos, México, El Colegio de México.

Espinoza Soriano, Waldemar (2009), «El carácter de la independencia y años aurorales de la república del Perú. Comentario analítico y crítico». Illapa $\mathrm{N}^{\circ}$ 4. Lima-julio, pp. 7597.

Favre, Henry (1969), «El desarrollo y las formas del poder oligárquico en el Perú». Borricaud, Francois et.al. La oligarquía en el Perú, Lima, IEP.

Flórez Estrada, Álvaro (1811), Examen imparcial de las disensiones de la América con la España, Londres.

Flores Galindo, Alberto (1991), La ciudad sumergida. Aristocracia y plebe en Lima, 176o1830, Lima, Edit. Horizonte, 2da edic.

Freyre, Maynor (1987) «Buscando entender y cambiar el Perú», Altavoz de domingo $\mathrm{N}^{\circ}$ 49, Lima, 16-ago-1987, pp. 4-5.

Gonzáles, Osmar y Martha García (1987), «Independencia inconclusa. ¿Quién cumplirá promesa de la vida peruana?», Altavoz de domingo, № 46, Lima, 26-jul-1987, pp. 1112.

Gootenberg, Paul (1989), Caudillos y comerciantes. La formación económica del Estado peruano, 1820-186o, Cuzco, CERA “Bartolomé de Las Casas”.

Hamnett, Brian (1978), Revolución y contrarrevolución en México y el Perú, México, FCE.

Huaraj, Juan Carlos (2010), «La pérdida de América según Manuel Lorenzo Vidaurre. De la fidelidad al Rey a la del Supremo Estado del Perú: 1812-1833», Ukupacha $\mathrm{N}^{\circ} 15$. Lima-julio, pp. 121-135.

Lazo, Carlos (1993), “Tres tesis cuestionables sobre la conquista y colonización castellana de América”, Sequilao No 3, pp. 86-89.

Lazo, Carlos (2004), "Ideas y conceptos constitutivos de la teoría del poder político durante el virreinato”, Investigaciones Sociales N 12, UNMSM/IIHS, pp. 203-212 
Lazo, Carlos y Alex Ortegal (1999), El concepto nación en el proceso histórico peruano.Cuestiones teóricas, Lima, Mec., Inéd.

Lazo, Carlos y Carlos Morales (2003), "Ensayo crítico sobre la filosofía de la historia en la obra de Jorge Basadre”. Investigaciones Sociales No 11. UNMSM/IIHS, pp. 303-311.

Lora Cam, José. (1988), La guerra 1879-1979: Chile-Bolivia-Perú, Arequipa, Edit. Tercer Mundo.

Macera, Pablo (1976), La imagen francesa del Perú, Lima, INC.

Méndez, Cecilia (2014), La república plebeya. Huanta, formación del Estado peruano, 1820185o, Lima, IEP.

Monteagudo, Bernardo (1823), Memoria sobre los principios políticos que seguí en la administración del Perú, y acontecimientos posteriores a mi separación. Quito.

Palza Becerra, Héctor (2008), Estado y política en una economía globalizada liberal. Tecnocracia, profesionalización y agencia comercial. Perú, 1760-180o, Lima.

Pérez Valdivia, Javier (2008), «El republicanismo liberal de José Faustino Sánchez Carrión: entre la teoría y la práctica», Illapa $\mathrm{N}^{\circ}$ 2. Lima-septiembre, pp. 117-137.

Reyes, Alejandro (1998), "La familia Montero: Empresarios nacionales, siglo XIX". Actas del I Encuentro Internacional de Peruanistas. Estado de los estudios histórico-sociales sobre el Perú del siglo XIX, T. I, Lima, Universidad de Lima, pp. 501-532.

Riva Agüero, José de la (1818), Manifestación histórica y política de la revolución de la América. Bs. As.

Sábato, Hilda (2006), "La reacción de América: la construcción de las repúblicas en el siglo XIX”, en Chartier Roger y Antonio Feros (comps.), Europa, América y el mundo: tiempos históricos, Madrid, Marcial Pons, pp. 263-280.

Sobrevilla, Natalia (2019), Los inicios de la república peruana. Viendo más allá de la «cueva de bandoleros», Lima, PUCP.

Vega, Juan José (1994). «Patria y Democracia», Gaceta Sanmarquina № 23. Lima, julio, p. 4.

Wills, Fritz (1979), Los industriales, la industrialización y el Estado Nación en el Perú, Lima, PUCP.

Yepes del Castillo (1972), Ernesto, Perú: 1820-1920. Un siglo de desarrollo capitalista, Lima, IEP/Campodónico ediciones. 